\title{
Experimental and Numerical Study of Chemiluminescence Characteristics in Premixed Counterflow Flames of Methane based Fuel blends
}

\author{
Yushuai Liu ${ }^{1}$, George Vourliotakis ${ }^{2}$, Yannis Hardalupas ${ }^{3}$ and A. M. K. P. Taylor ${ }^{4}$
} Imperial College London, Department of Mechanical Engineering, London SW7 2BX, U.K.

\begin{abstract}
Non-intrusive chemiluminescence measurements have been used as heat release rate and equivalence ratio indicators for gas turbine combustor active control. In the present study, measurements and modelling of $\mathrm{OH}^{*}, \mathrm{CH}(\mathrm{A})^{*}, \mathrm{C}_{2}{ }^{*}$, and $\mathrm{CO}_{2}{ }^{*}$ chemiluminescence are used to examine chemiluminescence sensing of heat release rate and equivalence ratio in premixed counterflow methane - air flames with equivalence ratio from 0.6 to 1.3 and strain rate from 80 to $400 \mathrm{~s}^{-1}$. Two spectrally resolved detecting optical systems were used to detect spatially-averaged (global) and spatially resolved (local) chemiluminescence characteristics in the reaction zone. A recently published reaction mechanism ${ }^{1}$ for the chemiluminescence of the $\mathrm{OH}^{*}, \mathrm{CH}^{*}$, and $\mathrm{C}_{2}{ }^{*}$ species is incorporated to GRI-Mech 3.0. The augmented mechanism is further validated against the experimental results of the present study and is used to predict the chemiluminescence characteristics of premixed counterflow methane - air flames. The mechanism includes $\mathrm{OH}^{*}$ chemiluminescence formation paths from hydrogen reaction, which have not been evaluated before in premixed counterflow flames. The CHEMKIN based counterflow flame code, OPPDIF is employed to simulate the experiments. The calculated $\mathrm{OH}^{*}$ and $\mathrm{CH}(\mathrm{A})^{*}$ chemiluminescence agrees well with the experimental results measured by both optical methods. Both the experimental and numerical results demonstrate the ability of $\mathrm{OH}^{*}$ and $\mathrm{CH}(\mathrm{A})^{*}$ intensities to mark heat release rate in methane - air flames. Overall, $\mathrm{CH}^{*}$ may be preferable for heat release rate sensing applications at elevated equivalence ratio and strain rate. For equivalence ratio sensing in methane combustion, the measured and simulated $\mathrm{OH}^{*} / \mathrm{CH}(\mathrm{A})^{*}$ chemiluminescent intensity ratio is highly dependent on equivalence ratio and nearly independent of strain rate. Thus, this ratio can be used to monitor equivalence ratio. However, a non-monotonic behavior of the $\mathrm{OH}^{*} / \mathrm{CH}^{*}$ ratio for very lean combustion $(\mathrm{ER}<0.7)$ is observed, in agreement with previous studies. This behavior can be reproduced by the reaction mechanisms. The behavior of $\mathrm{OH}^{*} / \mathrm{CH}(\mathrm{A})^{*}$ chemiluminescent intensity ratio for flames of methanepropane blends are also calculated with the detailed chemistry model. The addition of propane in methane modifies the behaviour of $\mathrm{OH}^{*} / \mathrm{CH}(\mathrm{A})^{*}$ chemiluminescent intensity ratio dramatically. However, the numerical results suggest that the $\mathrm{OH}^{*} / \mathrm{CH}(\mathrm{A})^{*}$ chemiluminescent intensity ratio is an indicator of equivalence ratio in lean methanepropane fuel blended flames.
\end{abstract}

\footnotetext{
${ }^{1}$ PhD student, Department of Mechanical Engineering, yushuai.liu14@imperial.ac.uk, AIAA Student Member

${ }^{2}$ Research Associate, Department of Mechanical Engineering, g.vourliotakis@imperial.ac.uk

${ }^{3}$ Professor, Department of Mechanical Engineering, y.hardalupas@imperial.ac.uk, AIAA Associate Fellow

${ }^{4}$ Professor, Department of Mechanical Engineering, a.m.taylor@imperial.ac.uk
} 


\section{Nomenclature}

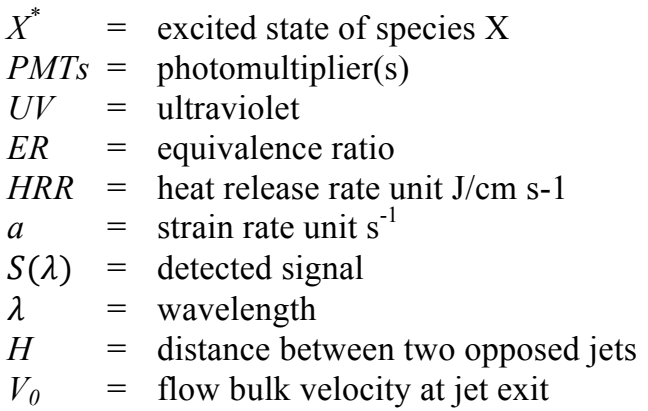

\section{Introduction}

The natural occurrence of visible and ultraviolet (UV) light emissions from methane flames is the result of the chemiluminescent emission of four major emitters: $\mathrm{OH}^{*}, \mathrm{CH}^{*}, \mathrm{C}_{2}{ }^{*}$, and $\mathrm{CO}_{2}{ }^{*}$. The $\mathrm{OH}^{*}$ presents its strongest UV emission at $309 \mathrm{~nm}$, from the $A^{2} \Sigma^{+}-X^{2} \Pi(\mathrm{A}-\mathrm{X})$ transition system, of the hydrocarbon flame spectra. Blue light emission from $\mathrm{CH}^{*}$ in hydrocarbon flames is from two different systems, referred to as $\mathrm{CH}(\mathrm{A})^{*}$ and $\mathrm{CH}(\mathrm{B})^{*}$, corresponding respectively to the $A^{2} \Delta-X^{2} \Pi$ transition at $431 \mathrm{~nm}$ and $B^{2} \Sigma^{-}-X^{2} \Pi$ transition at 390 $\mathrm{nm}$. The strongest emission of $\mathrm{C}_{2}^{*}\left(d^{3} \Pi-a^{3} \Pi\right)$, named Swan Band, is responsible of the greenish colour in stoichiometric and rich hydrocarbon flames. Three main heads are at 471, 516 and $563 \mathrm{~nm}^{2}$. Unlike the distinct spectroscopic features of $\mathrm{OH}^{*}, \mathrm{CH}^{*}$ and $\mathrm{C}_{2}{ }^{*}$, the chemiluminescence of $\mathrm{CO}_{2}{ }^{*}$ presents a continuous broadband emission from 240 to $800 \mathrm{~nm}^{3}$, which makes the detailed study of $\mathrm{CO}_{2}{ }^{*}$ chemiluminescent spectrum difficult ${ }^{4}$.

Chemiluminescence has been widely studied as a simple and nonintrusive optical diagnostic for gas turbine combustors. Numerous studies have investigated the ability of using chemiluminescent intensity as a marker to monitor the equivalence ratio $(\mathrm{ER})^{5-12}$, heat release rate $(\mathrm{HRR})^{5,6,9,13}$, NOx pollutant emission ${ }^{8,10,14,15}$ and flame front location ${ }^{16-18}$. The ratios of $\mathrm{OH}^{*} / \mathrm{CH}(\mathrm{A})^{*}$ and $\mathrm{C}_{2}{ }^{*} / \mathrm{CH}(\mathrm{A})^{*}$ chemiluminescent intensities could be utilized as indicators of equivalence ratio, because they provide a monotonic variation from lean to rich stoichiometry of flames for different hydrocarbon fuels ${ }^{12,19}$ and they are independent of flow strain rates ${ }^{5,20}$. However, this correlation between chemiluminescent intensities ratios and equivalence ratio has been reported to fail for hydrogen enriched methane flames ${ }^{21,22}$ and near the lean extinction limit of methane and natural gas flames $^{23-25}$. For instance, García-Armingol and Ballester ${ }^{22}$ measured the chemiluminescent emission in hydrogen enriched methane flames from $E R=0.58$ to $E R=1.0$ and found that the slope of $\mathrm{OH}^{*} / \mathrm{CH}(\mathrm{A})^{*}$ as function of ER decreased as the percentage of hydrogen in the $\mathrm{H}_{2}-\mathrm{CH}_{4}$ fuel mixture increased and then the $\mathrm{OH}^{*} / \mathrm{CH}(\mathrm{A})^{*}$ ratio became insensitive to ER. Zimmer et al. ${ }^{25}$ conducted photomultiplier tube (PMTs) based measurements of the $\mathrm{OH}^{*} / \mathrm{CH}(\mathrm{A})^{*}$ ratio as a function of ER (range from 0.4 to 0.9 ) near the lean extinction limits of $\mathrm{CH}_{4}$ flames in a swirl burner and found that the $\mathrm{OH}^{*} / \mathrm{CH}(\mathrm{A})^{*}$ changed non-monotonically. Furthermore, the chemiluminescent intensities of $\mathrm{OH}^{*}, \mathrm{CH}(\mathrm{A})^{*}, \mathrm{C}_{2}{ }^{*}$, and $\mathrm{CO}_{2}{ }^{*}$ are used to indicate the local HRR and integral HRR of flames in different kind or burners $5,6,13,26,27$. However, in highly turbulent flames, the chemiluminescent intensities show a disability to indicate the local HRR because of local quenching of chemiluminescence ${ }^{13,26}$.

On the other hand, because of the ease of implementation of chemiluminescence measurements for combustion monitoring, chemical kinetics models of the $\mathrm{OH}^{*}, \mathrm{CH}(\mathrm{A})^{*}, \mathrm{C}_{2}{ }^{*}$ and $\mathrm{CO}_{2}{ }^{*}$ chemiluminescence chemistries have been studied by many researchers. Generally, the available reaction mechanisms consist of three steps: first, formation of excited state molecules; second, collisional quenching reactions that remove the excited state, reducing excited state molecules to their ground electronic configuration; and third, radiative transitions to the ground state. Among these steps, the formation steps are the most important but difficult to quantify its reaction rate. For $\mathrm{OH}^{*}$ formation, the following formation paths have been extensively proposed:

$$
\begin{gathered}
\mathrm{H}+\mathrm{O}+\mathrm{M} \leftrightarrow \mathrm{OH}^{*}+\mathrm{M} \\
\mathrm{CH}+\mathrm{O}_{2} \leftrightarrow \mathrm{OH}^{*}+\mathrm{CO}
\end{gathered}
$$

Reaction (R2) is typically presented as the main formation reaction in hydrocarbon flames, while reaction (R1) is activated in hydrogen flames. Moreover, the radiative decay of $\mathrm{OH}^{*}$ and collisional quenching process can be described by the following reactions:

$$
\begin{gathered}
\mathrm{OH}^{*} \leftrightarrow \mathrm{OH}+\mathrm{h} v \\
\mathrm{OH}^{*}+\mathrm{M} \leftrightarrow \mathrm{OH}+\mathrm{M}
\end{gathered}
$$


where $\mathrm{M}$ is the colliding species. Similar, for $\mathrm{CH}(\mathrm{A})^{*}$ chemiluminescence, three steps reaction models have been widely researched. However, for $\mathrm{C}_{2}{ }^{*}$ and $\mathrm{CO}_{2}{ }^{*}$ reactions, limited information has reported the reaction rates of their formation reactions ${ }^{4,28,29}$.

Although a lot of effort has gone into measuring the reaction rates of the excited species formation reactions, the reaction rates measured by different researchers are not in close agreement. For example, the reaction rates of the $\mathrm{OH}^{*}$ formation reactions measured by Hall and Petersen ${ }^{30}$ are three to four orders higher than Bozkurt and Metehan $^{31}$ measurements. Most of the reaction rate calibrations are based on shock tube experiments, which cannot compare the chemiluminescent behaviour between different excited species. Moreover, because of lack of experimental data, the chemical kinetics models of $\mathrm{C}_{2}{ }^{*}$ and $\mathrm{CO}_{2}{ }^{*}$ are still open issues. Thus, the measured chemiluminescence of $\mathrm{OH}^{*}, \mathrm{CH}(\mathrm{A})^{*}, \mathrm{C}_{2}{ }^{*}$ and $\mathrm{CO}_{2}{ }^{*}$ and their ratios as the calibrating database for chemiluminescence reaction models are widely required.

In the present research, a premixed counterflow burner was employed to provide physical and chemical insight of $\mathrm{OH}^{*}, \mathrm{CH}(\mathrm{A})^{*}, \mathrm{C}_{2}{ }^{*}$ and $\mathrm{CO}_{2}{ }^{*}$ chemiluminescence. Counterflow burner flames provide an essential onedimensional (1-D) geometry, thus, they can be described well by simplified computational models. Both lineof-sight and spatially resolved collection optics are employed to provide spectrally, spatially and time resolved chemiluminescent behaviour, including $\mathrm{OH}^{*}, \mathrm{CH}(\mathrm{A})^{*}, \mathrm{C}_{2}{ }^{*}$ and $\mathrm{CO}_{2}{ }^{*}$ in premixed counterflow flames with different fuel blends. The measured qualitative chemiluminescent intensities and quantitative intensity ratios of these chemiluminescent emissions can provide a database to validate the chemical kinetic models and to calibrate combustion diagnostics. Moreover, based on these experimental results, we simultaneously examine the available chemical reaction models of $\mathrm{OH}^{*}, \mathrm{CH}(\mathrm{A})^{*}, \mathrm{C}_{2}{ }^{*}$ and $\mathrm{CO}_{2}{ }^{*}$ and evaluate their ability to predict chemiluminescent behaviour of different fuel mixtures.

\section{Experimental apparatus}

\section{A Counterflow burner}

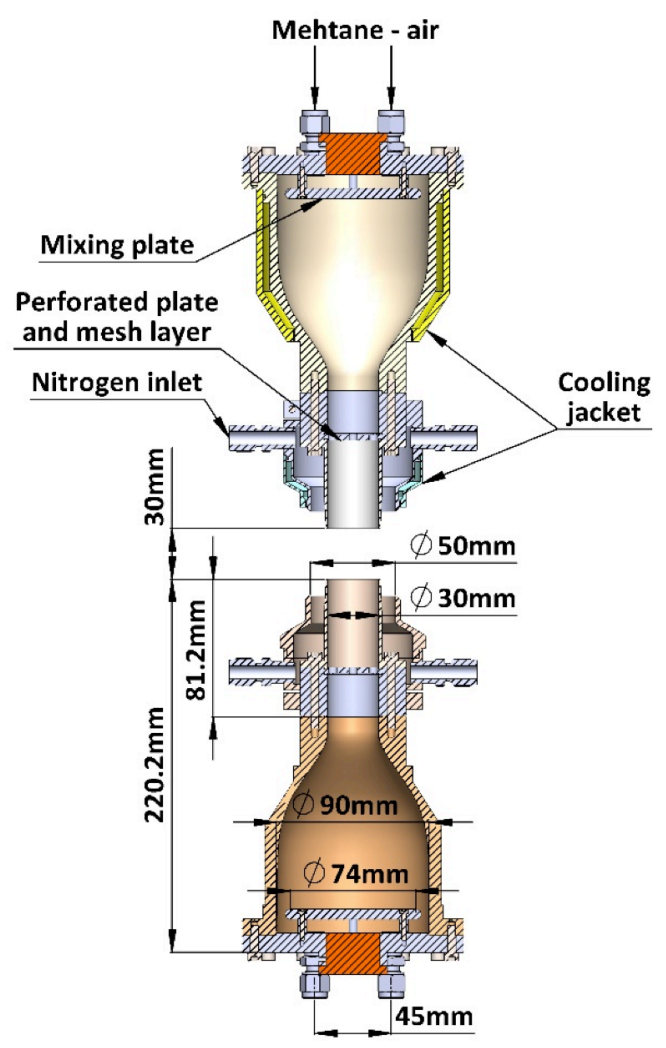

Figure. 1 The experimental arrangement of the counterflow burner.
The counterflow burner was employed because it can provide the possibility of controlling, independently, the equivalence ratio of the reactants and the global strain rate of the flame. The generated flat flames are stabilized close to the stagnation plane and there is good optical access for the chemiluminescence measurements. In addition, the 1-D flames counterflow burner can be easily described by standard numerical codes for further numerical investigations.

The counterflow burner used for this work is shown in Figure. 1 5, 6, 19,32. It consisted of two identical, vertically opposed contracting nozzles with inner diameter of $30 \mathrm{~mm}$, separated by a distance of $30 \mathrm{~mm}(\mathrm{H}=30 \mathrm{~mm})$. The methane and air supply flows were supplied into both opposed nozzles and initially impinged on round plates to ensure adequate premixing. The two opposed nozzles were carefully aligned to ensure the velocity profiles at the burner exit were axisymmetric. The external annular flow was used to provide nitrogen $\left(\mathrm{N}_{2}\right) . \mathrm{N}_{2}$ was introduced from four side inlets, passed through a honeycomb mesh, and exited from an annular ring surrounding the main nozzle. For stoichiometric and rich premixed flames, the $\mathrm{N}_{2}$ co-flows were used to extinguish the diffusion flames, formed away from the central flat flame and ensure the premixed flames were detached from the exit nozzle rims.

For this burner configuration, the ER of the mixture was varied from 0.6 to 1.3 , and the area averaged velocity of the gas mixture at the jet exit, $\mathrm{V}_{0}$, was varied from 1.2 to $6 \mathrm{~m} / \mathrm{s}$, which corresponded to a global flow strain rate range from 80 to $400 \mathrm{~s}^{-1}$. The calculation of this strain rate is based on the area averaged bulk velocity 
as $a=2 V_{0} / H$, where $\mathrm{H}$ is the distance between the two opposed nozzles. The inlet temperature of the premixed fuel-air mixture is $300 \mathrm{~K}$.

\section{B Optical systems}

$1 \quad$ Spectrally resolved line of sight detection system

The Spectrally resolved chemiluminescence was measured by a fibre-lens optical Echelle spectrograph, shown in Figure. 2. The light was collected by a UV fused silica plano-convex lens and focused on a UV-grade optical fibre (Thorlabs lnc, FT1500UMT) with core diameter of $1500 \mu \mathrm{m}$. A mask was fitted in front of the lens to minimize the collection of ambient light and secondary flame light emission. The collected light was directed to a $25 \mu \mathrm{m} \times 50 \mu \mathrm{m}$ slit, subsequently delivered to a high resolution Echelle spectrograph (Andor, Mechelle ME5000) and detected by an ICCD camera (Andor, DH-534). This spectrally resolved line of sight detection system can provide both a wide wavelength range from 250 to $800 \mathrm{~nm}$ and a high wavelength resolution of $\Delta \lambda \approx \lambda / 4000 \mathrm{~nm}$.

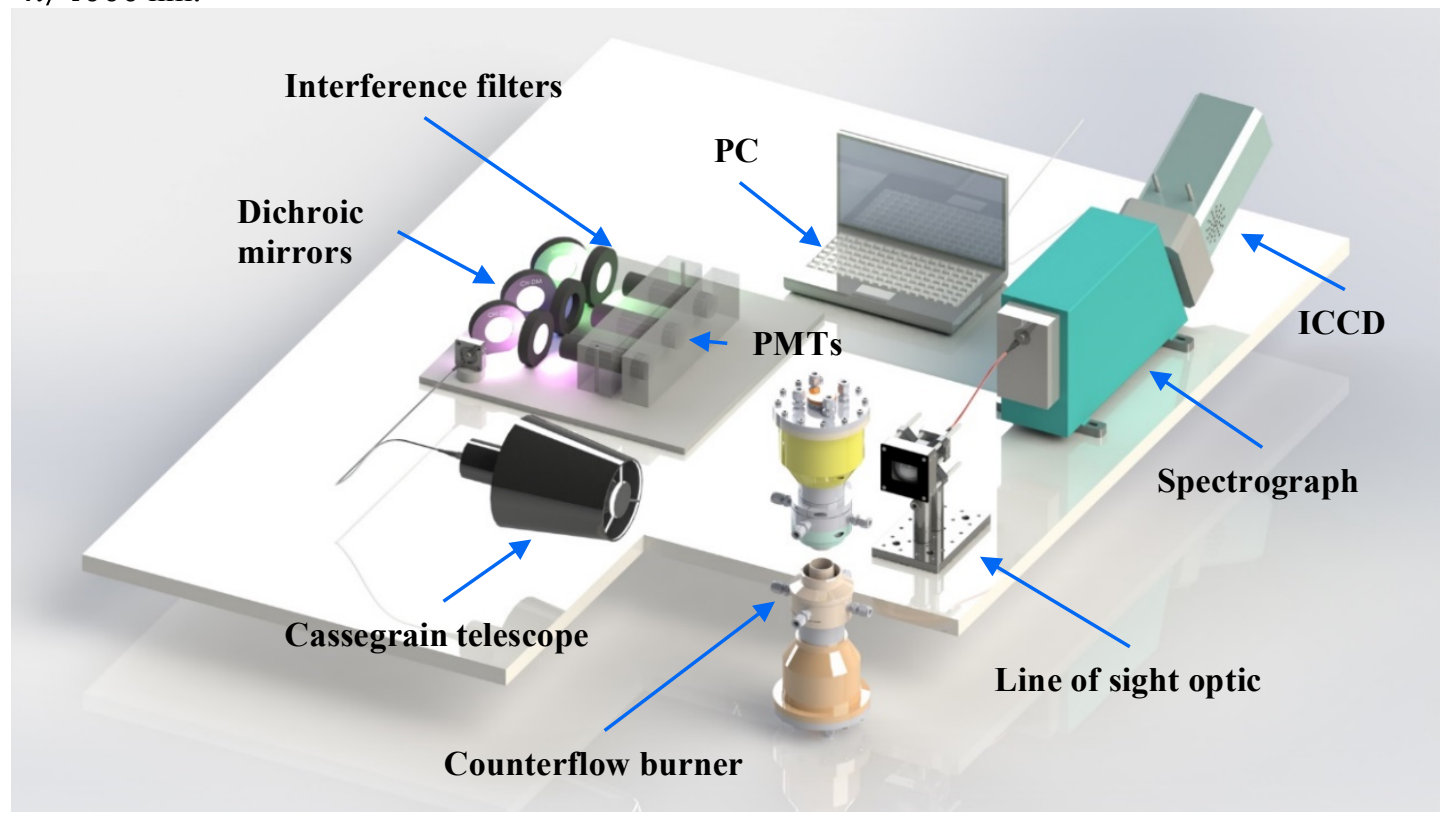

Figure. 2 The experimental arrangement of two optical detection systems and the flow

\section{Spatially and time resolved detection system}

The spatially and temporally resolved detection system is a MICRO (Multi-colour Integrated Cassegrain Receiving Optics) system ${ }^{33,34}$, modified in previous studies ${ }^{5,6}$. The Cassegrain-based optical Sensor (CS) with the working distance of $300 \mathrm{~mm}$ had a primary and a secondary mirror of 150 and $50 \mathrm{~mm}$ diameters respectively, see Figure. 2. This ensured a probe volume of the sensor with nominal diameter of $200 \mu \mathrm{m}$ and length of 1.6 $\mathrm{mm}^{6}$. There are two main advantages of the CS over the line of sight: one is avoiding chromatic aberrations for different wavelengths ${ }^{33}$, another is reducing the contribution of flame emissions from outside the probe volume ${ }^{6}$, 33. The collected light from the CS was focused onto a pinhole placed in front of a UV-grade optical fibre (Thorlabs lnc, FT1500UMT), whose core diameter is $1500 \mu \mathrm{m}$ and Numerical Aperture (NA) is 0.39 . The light was subsequently delivered to a purpose-built spectroscopic unit (Figure. 2). The light was collimated and separated into three spectral fractions using two dichroic mirrors (Optical Coatings Japan) with efficiencies greater than $95 \%$. Each part was directed onto appropriate interference filters specific to the considered radical, at $308.5 \mathrm{~nm}$ for the $\mathrm{OH}^{*}, 430.5 \mathrm{~nm}$ for the $\mathrm{CH}^{*}$, and $516.0 \mathrm{~nm}$ for the $\mathrm{C}_{2}{ }^{*}$ with corresponding efficiencies of $22.0,45.3,71.7 \%$ and with bandwidths of $18.0 \mathrm{~nm}, 1.9 \mathrm{~nm}$ and $2.3 \mathrm{~nm}$ respectively. The collected light intensities were transformed into electrical signals by using three identical photomultipliers (PMTs; Hamamatsu R269). The temporal electrical signals were then filtered, using passive low-pass filters (TTE) with $8 \mathrm{kHz}$ cutoff frequency and digitised using a 16-bit (PCI-6251, National Instruments) A/D card with sampling frequency of $100 \mathrm{kHz}$. The data processing procedure used in the context of this work is the one suggested by Hardalupas and Orain ${ }^{5}$.

\section{Numerical Modelling}

The chemical kinetics mechanism used in this work consisted of GRI-Mech $3.0^{35}$, as the basic hydrocarbon mechanism, with an additional chemiluminescence sub-model adopted by Kathrotia et al. ${ }^{1,27}$. The $\mathrm{CO}_{2}{ }^{*}$ 
chemiluminescence model of Kopp et al. ${ }^{4,28}$ was included in the chemiluminescence sub-model. The reaction rate of R2 was updated, according to the recent shock-tube measurement from Bozkurt and Metehan ${ }^{31}$. The chemiluminescence sub-model requires, in addition to the chemiluminescent species, elementary reactions for $\mathrm{C}$, $\mathrm{C} 2$, and $\mathrm{C} 3$ species, which are important for predicting the $\mathrm{CH}^{*}$ and $\mathrm{C}_{2}{ }^{*}$. The entire mechanism contains 63 species and 846 elementary reactions. The thermochemical data of the base mechanism were retained from the GRI-Mech 3.0 ${ }^{35}$, while the thermochemical data of the sub-mechanism for excited species with additional reactions of $\mathrm{C}, \mathrm{C} 2$, and $\mathrm{C} 3$ species have been adopted by the Burcat-Ruscic database ${ }^{36}$. The OPPDIF ${ }^{37}$ code of the Chemkin II collection was employed to simulate the 1-D premixed flames. The operating conditions of strain rate and equivalence ratio in the calculation are consistent with the experiments, which enable a direct comparison between experimental and numerical results.

\section{Results and discussion}

\section{A Global $\mathrm{OH}^{*}, \mathrm{CH}(\mathrm{A})^{*}, \mathrm{C}_{2}{ }^{*}$, and $\mathrm{CO}_{2}{ }^{*}$ Chemiluminescence in the Methane-Air Flames}

In this section, global chemiluminescent intensities of $\mathrm{CO}_{2}{ }^{*}, \mathrm{OH}^{*}, \mathrm{CH}(\mathrm{A})^{*}$ and $\mathrm{C}_{2}{ }^{*}$ are reported. The ability of using global chemiluminescence to infer heat release rate and equivalence ratio is evaluated in this section of the paper.

\section{Global chemiluminescent intensity of $\mathrm{CO}_{2}{ }^{*}, \mathrm{OH}^{*}, \mathrm{CH}(\mathrm{A})^{*}$, and $\mathrm{C}_{2}{ }^{*}$}

$\mathrm{CO}_{2}{ }^{*}$ chemiluminescence has been suggested as a HRR indicator by several studies. It is the main contributor of background emission at the wavelengths of other chemiluminescent species. $\mathrm{CO}_{2}{ }^{*}$ chemiluminescent intensity is discussed preferentially before other main chemiluminescent emissions.

The global $\mathrm{CO}_{2}{ }^{*}$ background emission intensities at different wavelength ranges are evaluated and plotted in Figure. 3(a) after normalizing by the maximum intensity. Since the global $\mathrm{CO}_{2}{ }^{*}$ emissions are decreased with increasing wavelength, the contribution of $\mathrm{CO}_{2}{ }^{*}$ chemiluminescent intensity at the $\mathrm{OH}^{*}$ spectral range was estimated by the following equation:

$$
I_{C O_{2}^{*} O H^{*}}=0.5 \times\left[\int_{294 n m}^{296 n m} S(\lambda) d \lambda+\int_{332 n m}^{334 n m} S(\lambda) d \lambda\right]
$$

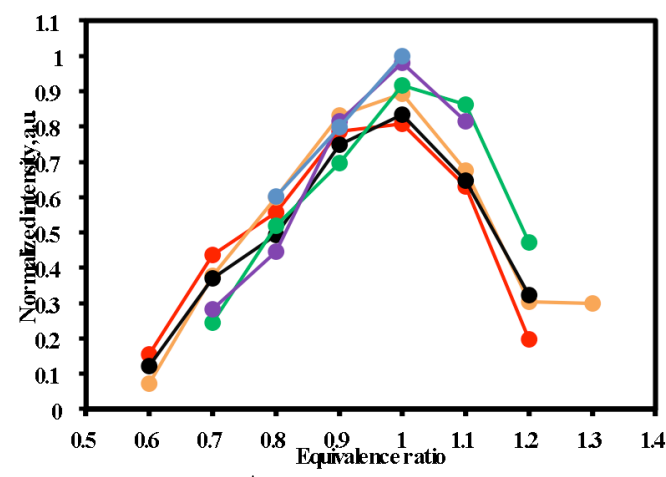

a) Normalized $\mathrm{CO}_{2}{ }^{*}$ chemiluminescent intensity

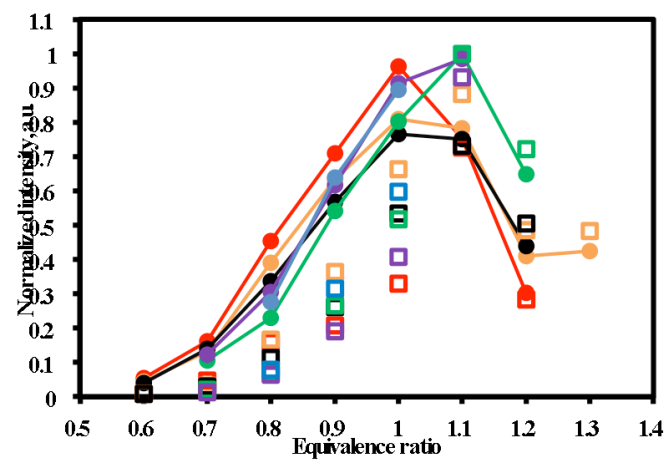

c) Normalized $\mathrm{CH}(\mathrm{A})^{*}$ chemiluminescent intensity

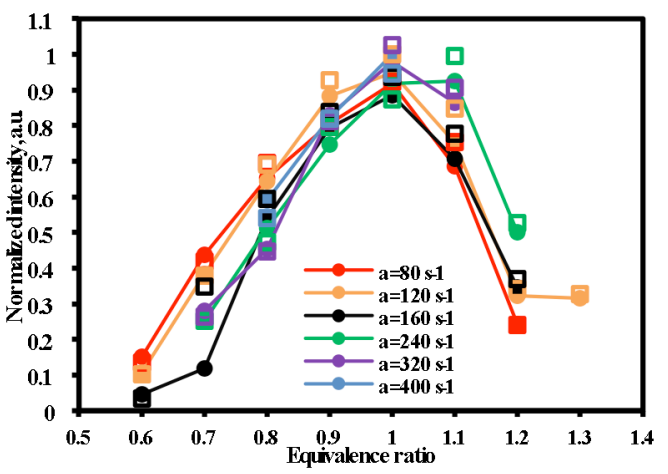

b) Normalized $\mathrm{OH}^{*}$ chemiluminescent intensity.

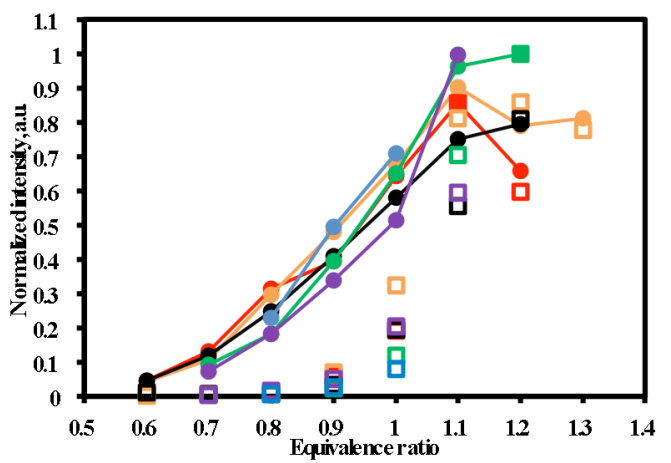

d) Normalized $\mathrm{C}_{2}{ }^{*}$ chemiluminescent intensity

Figure. 3 Global chemiluminescent intensity, normalized by the maximum recorded value, emitted from $\mathrm{OH}^{*}$, $\mathrm{CH}(\mathrm{A})^{*}$ and $\mathrm{C}_{2}^{*}$ after background emission correction (open squares) and without background emission correction (solid circles). In addition, the global chemiluminescent intensity emitted from $\mathrm{CO}_{2}{ }^{*}$ normalised by the corresponding maximum recorded value, is presented.

The measured $\mathrm{CO}_{2}{ }^{*}$ intensity showed the maximum value at stoichiometry for all six strain rates, shown in Figure. 3(a). This result suggests that the $\mathrm{CO}_{2}{ }^{*}$ intensity can be used to indicate the HRR, because the HRR has 
a maximum at stoichiometry ${ }^{20}$. The contributions of the $\mathrm{CO}_{2}{ }^{*}$ intensity at the $\mathrm{CH}^{*}(\mathrm{~A})^{*}$ and $\mathrm{C}_{2}{ }^{*}$ spectral ranges were similar to that at the $\mathrm{OH}^{*}$ wavelength range and are not presented here.

Figure. 3(b), Figure. 3(c) and Figure. 3(d) show the normalized global $\mathrm{OH}^{*}, \mathrm{CH}(\mathrm{A})^{*}$ and $\mathrm{C}_{2}{ }^{*}$ chemiluminescent intensities with and without background emission. Similar to $\mathrm{CO}_{2}{ }^{*}$ chemiluminescent intensity, the chemiluminescent intensities from $\mathrm{OH}^{*}$ and $\mathrm{CH}(\mathrm{A})^{*}$ with and without background emission, had maximum values at ER=1.0 or 1.1 for all examined strain rates, shown in Figure. 3(b) and Figure. 3(c). Thus, these two kinds of chemiluminescence can be employed as HRR indicators. However, $\mathrm{C}_{2}{ }^{*}$ intensity showed maximum values at $\mathrm{ER}=1.1$ or 1.2 , see Figure. $3(\mathrm{~d})$. The $\mathrm{OH}^{*}$ intensity had flatter profiles compared to that of $\mathrm{CH}(\mathrm{A})^{*}$, especially for the results without background intensity. This is expected and has been previously reported in experimental results ${ }^{2,5}$, but was not calculated numerically ${ }^{20}$. In addition, experimental results with the Cassegrain - PMT system were not reported and are shown here in Figure. 5. Moreover, a difference can be observed between the chemiluminescent intensities with and without the background emitted from $\mathrm{CH}(\mathrm{A})^{*}$ and $\mathrm{C}_{2}{ }^{*}$. The relative lower chemiluminescent intensities without the background from $\mathrm{CH}(\mathrm{A})^{*}$ and $\mathrm{C}_{2}{ }^{*}$ for lean flames are expected, because of the higher contribution from $\mathrm{CO}_{2}{ }^{*}$ at these flames. Thus, the $\mathrm{CO}_{2}{ }^{*}$ chemiluminescent emission should be considered when using $\mathrm{CH}(\mathrm{A})^{*}, \mathrm{C}_{2}{ }^{*}$ and $\mathrm{OH}^{*} / \mathrm{CH}(\mathrm{A})^{*}$ as indicators of flame properties.

\section{Global Chemiluminescent intensity ratios}

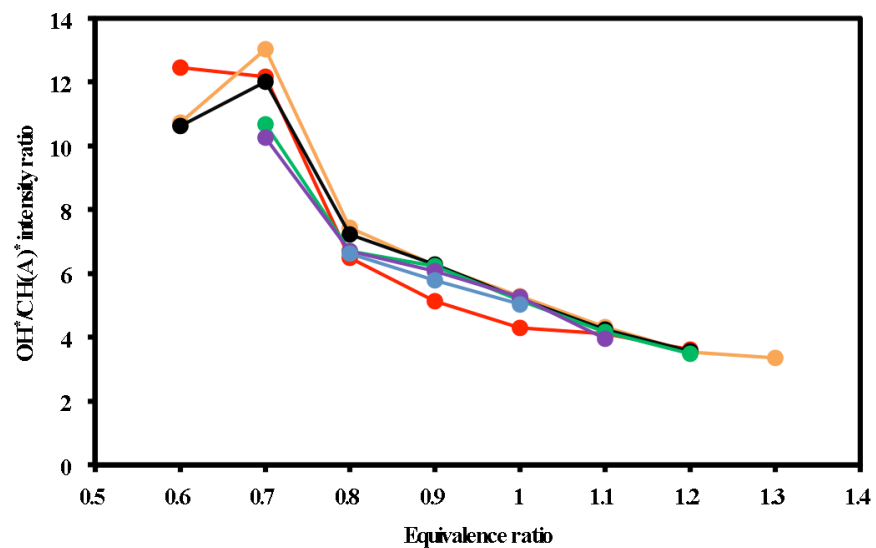

Figure. 4 Global chemiluminescent intensity ratios of $\mathrm{OH} / \mathrm{CH}(\mathrm{A}) *$ without correcting for the background emission intensity.

Figure. 4 shows the $\mathrm{OH}^{*} / \mathrm{CH}(\mathrm{A})^{*}$ chemiluminescent intensity ratio without removing the background intensity as a function of ER. The $\mathrm{OH}^{*} / \mathrm{CH}(\mathrm{A})^{*}$ decreased monotonically as the equivalence ratio increased from 0.7 to 1.3 . However, the $\mathrm{OH}^{*} / \mathrm{CH}(\mathrm{A})^{*}$ increased slightly as ER increased from 0.6 to 0.7 for a=120 s-1 and 160 $\mathrm{s}^{-1}$. This has been reported by several studies ${ }^{9,23-25,38}$ and it may be due to the chemiluminescent behaviour close to extinction and the contribution of background emission from $\mathrm{CO}_{2}{ }^{*}$.

\section{B Local $\mathrm{OH}^{*}, \mathrm{CH}(\mathrm{A})^{*}$, and $\mathrm{C}_{2}{ }^{*}$ Chemiluminescence in the Methane-Air Flames}

The spatially resolved distribution of $\mathrm{OH}^{*}, \mathrm{CH}^{*}$ and $\mathrm{C}_{2}{ }^{*}$ chemiluminescence was measured by the Cassegrain - PMTs system in the present study. Firstly, the local chemiluminescent intensity at the flame front location is presented. Then, the chemiluminescent intensity ratios are reported.

\section{Local $\mathrm{OH}^{*}, \mathrm{CH}^{*}$, and $\mathrm{C}_{2}{ }^{*}$ chemiluminescent intensities at the flame front}

Heat release rate is known to depend on parameters such as equivalence ratio, fuel mass flow rate, preheat temperature of mixture, pressure and local flame strain rate. The definition of heat release rate is the heat released due to chemical reactions per unit time and unit volume (i.e. units of $\mathrm{J} / \mathrm{m}^{3} \mathrm{~s}$ ).

Figure. 5 shows the normalized $\mathrm{OH}^{*}, \mathrm{CH}^{*}$ and $\mathrm{C}_{2}{ }^{*}$ local chemiluminescent intensities at the flame front. It is shown that, for equivalence ratio values from 0.6 to 1.2 , the $\mathrm{OH}^{*}, \mathrm{CH}^{*}$ and $\mathrm{C}_{2}{ }^{*}$ chemiluminescent intensity increased with strain rate from 160 to $400 \mathrm{~s}^{-1}$, which is consistent with the literature ${ }^{5}$. Both $\mathrm{OH}^{*}$ and $\mathrm{CH}^{*}$ chemiluminescence are maximized near the stoichiometric conditions ( $\mathrm{ER}=1.0$ for $\mathrm{OH}^{*}$ and $\mathrm{ER}=1.1$ for $\mathrm{CH}^{*}$ ). On the contrary, $\mathrm{C}_{2}{ }^{*}$ chemiluminescent intensity was increased monotonically from $\mathrm{ER}=0.6$ to $\mathrm{ER}=1.2$ for $\mathrm{a}=80$, $160-400 \mathrm{~s}^{-1}$ and then decreased at $\mathrm{ER}=1.3$ for $\mathrm{a}=120 \mathrm{~s}^{-1}$. The above suggest that $\mathrm{CH}^{*}$ chemiluminescence is a better heat release rate indicator than $\mathrm{OH}^{*}$, while, the $\mathrm{C}_{2}{ }^{*}$ is not an indicator. Overall, the equivalence ratio has a 
more prominent effect on the chemiluminescent intensity as compared to the effect of the strain rate.

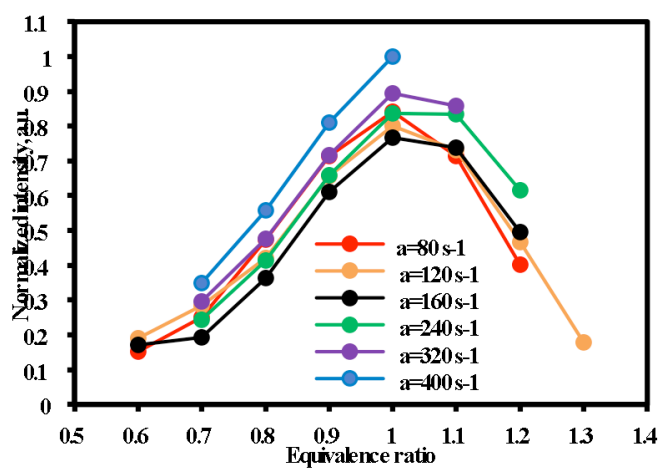

a) Normalized $\mathrm{OH}^{*}$ chemiluminescent intensity.

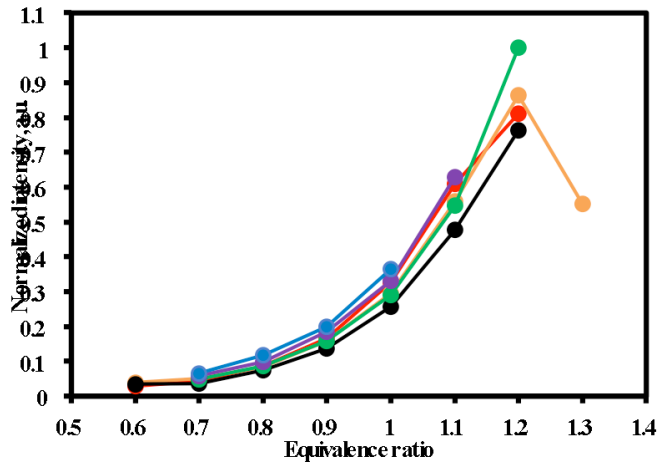

c) Normalized $\mathrm{C}_{2}{ }^{*}$ chemiluminescent intensity

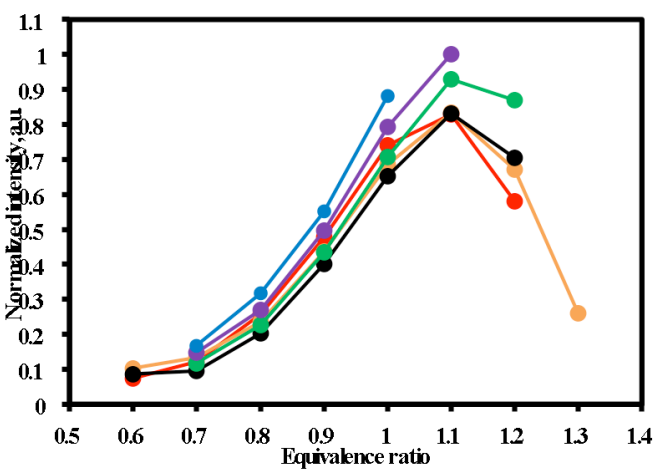

b) Normalized $\mathrm{CH}(\mathrm{A})^{*}$ chemiluminescent intensity

Figure. 5 Local chemiluminescent intensity emitted from $\mathrm{OH}^{*}, \mathrm{CH}(\mathrm{A}) *$ and $\mathrm{C}_{2} *$, normalized by the corresponding maximum recorded value.

\section{Local Chemiluminescent intensities ratios at the flame surface}

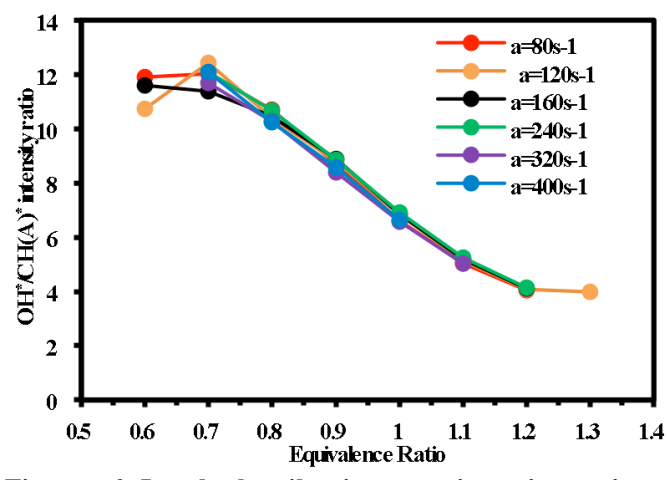

Figure. 6 Local chemiluminescent intensity ratios of $\mathbf{O H} * / \mathbf{C H}(\mathrm{A}) *$.

The ratio of $\mathrm{OH}^{*}$ chemiluminescent intensity over $\mathrm{CH}(\mathrm{A})^{*}$ chemiluminescent intensity is plotted in Figure. 6. The local chemiluminescent intensity ratios, agreed well with the global chemiluminescent intensity ratios, shown in Fig. 4. The $\mathrm{OH}^{*} / \mathrm{CH}(\mathrm{A})^{*}$ chemiluminescent intensity ratio measured by the Cassegrain-PMT system is slightly higher than that measured by the line of sight spectrographic system for the equivalence ratio range from 0.8 to 1.2 . This may be due to the different collecting optical arrangements. Similar to the global $\mathrm{OH}^{*} / \mathrm{CH}(\mathrm{A})^{*}$ intensity ratio, the local $\mathrm{OH}^{*} / \mathrm{CH}(\mathrm{A})^{*}$ intensity ratio without removing the background contribution is also non-monotonic with equivalence ratio at ER between 0.6 and 0.7 due to the behaviour of the $\mathrm{CO}_{2}{ }^{*}$ chemiluminescence background emission, which makes the ratio unable to indicate the equivalence ratio for ultra-lean methane-air flames.

\section{Calculated $\mathrm{OH}^{*}$ and $\mathrm{CH}^{*}$ chemiluminescence behaviour in methane-air flames}

In this section, the calculated $\mathrm{OH}^{*}$ and $\mathrm{CH}^{*}$ chemiluminescent behaviour is discussed. First, the flame structure and precursors of chemiluminescence are examined and verified by previous results. Then, the distance between the actual HRR peak and the maximum of chemiluminescent intensities from different species, which are used as HRR markers, as well as the distance between maximum intensity from different types of chemiluminescence are discussed. Finally, a comparison between calculated and measured chemiluminescence is provided to evaluate the chemiluminescence sub-model.

$1 \quad$ Flame structure and Peak-to-Peak Distance Between HRR and Chemiluminescence Markers

In order to explore the effect of the presence of the additional chemiluminescence sub-model on the characteristics of the flame, namely, the temperature, HRR, fuel, oxidant and main chemiluminescence precursors profiles are plotted in Figure. 7 for the case of $E R=0.7$ and $a=80 \mathrm{~s}-1$. There is no noticeable difference on the temperature, HRR, fuel and oxidant profiles of the present numerical results of the augmented mechanism and the results of the unmodified GRI-Mech 3.0. 


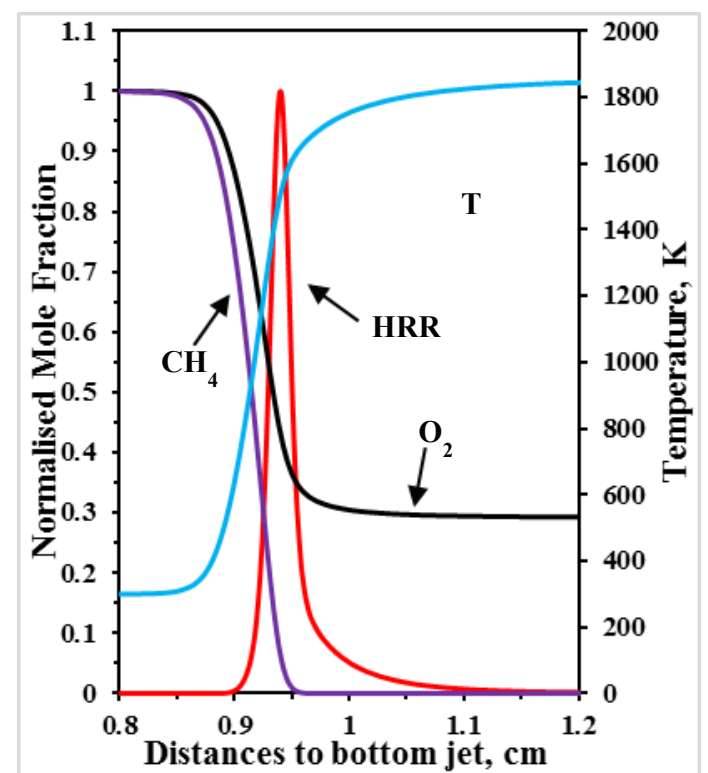

a) Calculated temperature, HRR, fuel and oxidant distributions in counterflow flames

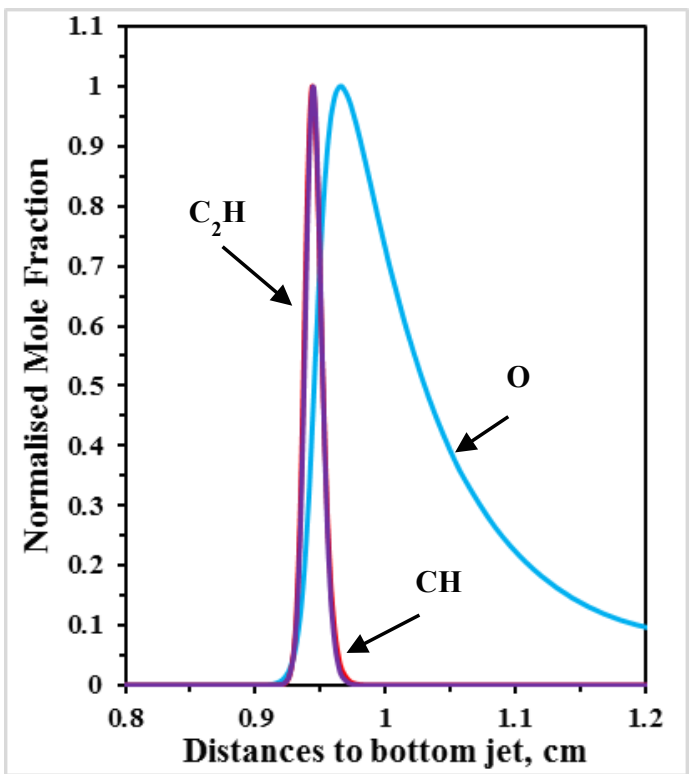

b) Calculated concentrations of $\mathrm{OH}^{*}$ and $\mathrm{CH}(\mathrm{A})^{*}$ precursors

Figure. 7 Effect of the addition of chemiluminescence sub-model on (a) temperature, $\mathrm{HRR}_{\text {and }}$ the $\mathrm{CH}_{4}, \mathrm{O}_{2}$ normalised mole

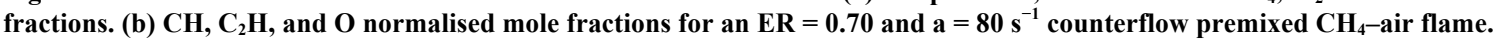

Figure. 8 shows the calculated peak to peak distance between $\mathrm{HRR}$ and $\mathrm{HCO}, \mathrm{OH} \times \mathrm{CH}_{2} \mathrm{O}, \mathrm{OH}^{*}$ and $\mathrm{CH}(\mathrm{A})^{*}$ for different equivalence ratios and strain rates. It is noted that $\mathrm{OH} \times \mathrm{CH}_{2} \mathrm{O}$ is the method that has been used experimentally to detect the HRR after Planar Induced Fluorescence measurements of $\mathrm{OH}$ and $\mathrm{CH}_{2} \mathrm{O}$ radicals. For all examined conditions, the peak to peak distance between $\mathrm{HRR}$ and $\mathrm{CH}(\mathrm{A})^{*}$ as well as $\mathrm{OH}^{*}$, are less than $60 \mu \mathrm{m}$, which is smaller than the calculated results of Panoutsos, Hardalupas and Taylor ${ }^{20}$; especially for $\mathrm{CH}(\mathrm{A})^{*}$, the peak to peak distance between HRR and $\mathrm{CH}(\mathrm{A})^{*}$ was reported between 60 and $110 \mu \mathrm{m}$ by Panoutsos, Hardalupas and Taylor ${ }^{20}$, while, in the present work, it is found to be between 40 and $60 \mu \mathrm{m}$. The $\mathrm{OH}^{*}, \mathrm{CH}(\mathrm{A})^{*}$ and $\mathrm{OH} \times$ $\mathrm{CH}_{2} \mathrm{O}$ have similar ability to indicate the HRR peak position, whereas the HCO showed a better performance than other HRR indicators in anchoring HRR peak position. Moreover, the strain rate and equivalence ratio can affect these distances; for instance, the peak to peak distance between HRR and $\mathrm{HCO}$ and $\mathrm{OH} \times \mathrm{CH}_{2} \mathrm{O}$ increased monotonically as ER changed from 0.6 to 1.3 .

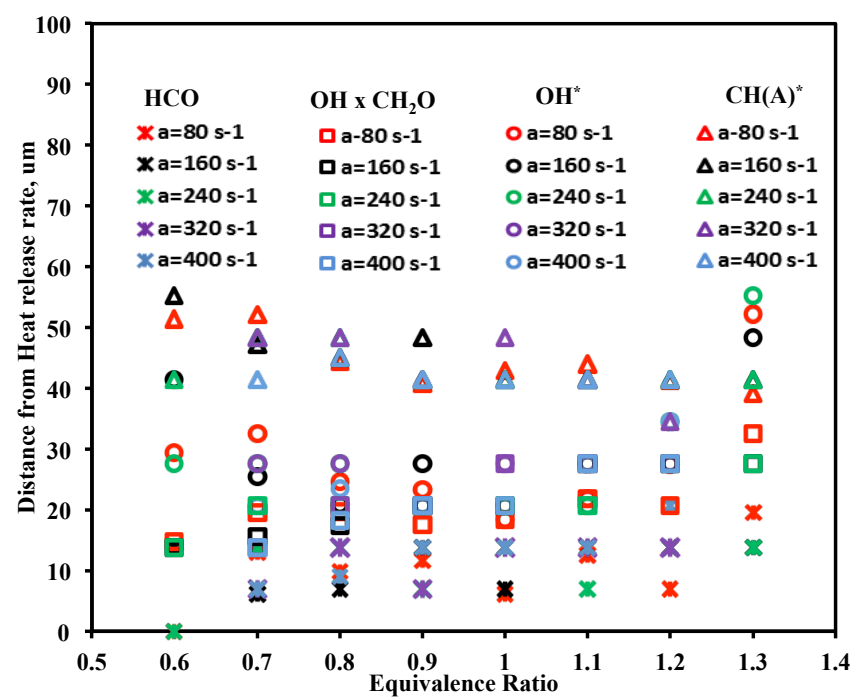

Figure. 8 Calculated peak to peak distance between real HRR and HCO, $\mathrm{OHxCH}_{2} \mathrm{O}, \mathrm{OH}^{*}$ and $\mathrm{CH}(\mathrm{A})^{*}$ as functions of $\mathrm{ER}$ and strain rate.

\section{Comparison of Experimental and Numerical Results}

Figure. 9(a) presents the calculated overall HRR and the calculated and measured $\mathrm{OH}^{*}$ chemiluminescent intensities as a function of equivalence ratio with strain rate as a parameter. The chemiluminescent intensity was calculated by the Rate of Production (ROP) of radiative reactions then normalised by its calculated maximum intensity. This calculated quantity represents the Cassegrain-PMTs measured chemiluminescent intensity. The $\mathrm{OH}^{*}$ chemiluminescent intensity increased monotonically with ER for all values of strain rate, for $0.6<\mathrm{ER}<1.1$, and decreased monotonically with increasing ER thereafter. According to the results of the calculations in the present study, the strain rate did not seem to have an effect on the heat release rate or the chemiluminescent intensity, for the lean range of ER, $0.6<\mathrm{ER}<0.9$, but there was an effect of strain rate on both calculated quantities on the rich side of ER, for ER $>0.9$. In contrast, the experimental results show that there was an effect 
of the strain rate for all the range of ER studied. The measured maximum $\mathrm{OH}^{*}$ intensity was found for $\mathrm{ER}=1.0$, while the calculated one was for $\mathrm{ER}=1.1$. The maximum calculated $\mathrm{OH}^{*}$ intensity correlated well with the maximum heat release rate for all values of strain rate, so this fact supports the argument that $\mathrm{OH}^{*}$ chemiluminescence can be used as heat release rate marker. Calculated HRR and normalised experimental/numerical $\mathrm{CH}^{*}$ intensity are plotted as a function of equivalence ratio with strain rate as a parameter in Figure. 9(b). The overall trends for the $\mathrm{CH}(\mathrm{A})^{*}$ intensities were the same as for $\mathrm{OH}^{*}$ intensities and followed also the same trend as heat release rate for $0.6<\mathrm{ER}<0.9$. The calculated maximum values of $\mathrm{CH}^{*}$ chemiluminescence as a function of ER with the strain rate as a parameter had the same trend with equivalence ratio as our experimental data. Moreover, unlike the observations for $\mathrm{OH}$, the maximum measured $\mathrm{CH}(\mathrm{A})^{*}$ intensity was for $\mathrm{ER}=1.1$, the same as the calculated one. $\mathrm{CH}(\mathrm{A})^{*}$ chemiluminescent intensity correlated well with the calculated maximum values of heat release rate, so $\mathrm{CH}(\mathrm{A})^{*}$ can be used as heat release rate marker.

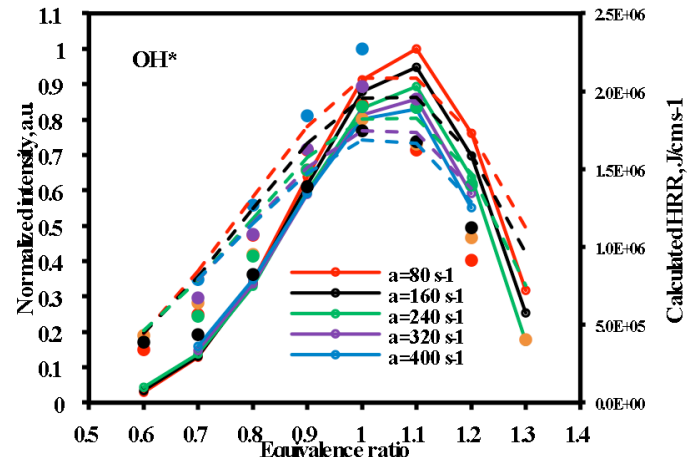

a) Calculated $\mathrm{OH}^{*}$ chemiluminescent intensity and HRR as well as experimental $\mathrm{OH}^{*}$ chemiluminescent intensity measured by PMTs system

Figure. 9 Calculated and measured $\mathrm{OH}^{*}$ and $\mathrm{CH}(\mathrm{A})^{*}$ chemiluminescent intensity, normalized by maximum value, and calculated overall HRR in counterflow burner flames with $E R=0.6-1.3$ and $a=80-400 \mathrm{~s}^{-1}$. The experimental chemiluminescent intensity results were measured by the Cassegrain-PMT system. The lines with circle refer to the numerical results of chemiluminescent intensity, the dots refer to the experimental results of chemiluminescent intensity and the dash lines refer to calculated HRR.

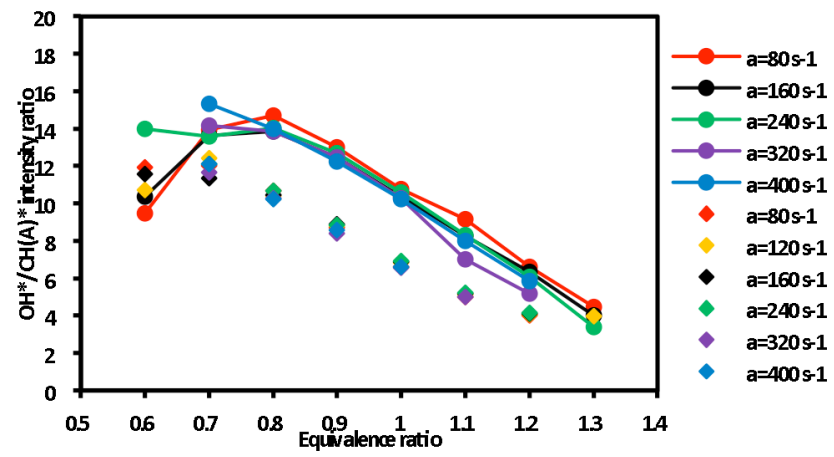

Figure. 10 Calculated and measured $\mathrm{OH}^{*} / \mathrm{CH}(\mathrm{A})^{*}$ chemiluminescent intensity ratio as a function of $\mathrm{ER}$ with the strain rate as a parameter. The lines with circle refers to numerical results and the diamonds refers to the experimental results.
The predicted and measured chemiluminescent intensity ratios are compared in Figure. 10. The trend of calculated $\mathrm{OH}^{*} / \mathrm{CH}(\mathrm{A})^{*}$ chemiluminescent intensity ratios monotonically increased for $0.6<\mathrm{ER}<0.8$, monotonically decreased for $0.8<\mathrm{ER}<1.3$ and had maximum value at $\mathrm{ER}=0.8$ for strain rate from 80 to $320 \mathrm{~s}^{-1}$. Whereas, for the $\mathrm{a}=400 \mathrm{~s}^{-1}$ case, the $\mathrm{OH}^{*} / \mathrm{CH}(\mathrm{A})^{*}$ chemiluminescent intensity ratio is monotonically decreasing with ER range from 0.7 to 1.2. However, for the experimental result measured by Cassegrain-PMTs system, the $\mathrm{OH}^{*} / \mathrm{CH}(\mathrm{A})^{*}$ chemiluminescent intensity ratio was nonmonotonic and had maximum at $\mathrm{ER}=0.7$ for

all the strain rates. Thus, the modified Kathrotia's sub-mechanism can predict the non-monotonic measured trend and the magnitude of $\mathrm{OH}^{*} / \mathrm{CH}(\mathrm{A})^{*}$ chemiluminescent intensity ratio, but cannot predict the $\mathrm{OH}^{*} / \mathrm{CH}(\mathrm{A})^{*}$ maximum at the appropriate equivalence ratio.

\section{The calculated chemiluminescent intensity ratios for methane-propane blended fuel flames}

To explore the fuel composition effect on the $\mathrm{OH}^{*} / \mathrm{CH}(\mathrm{A})^{*}$ chemiluminescent intensity ratio, the calculated $\mathrm{OH}^{*} / \mathrm{CH}(\mathrm{A})^{*}$ chemiluminescent intensity ratios in methane-propane blended fuel flames as a function of ER is shown in Figure. 11. Propane was blended with methane in mole fraction range from $5 \%$ to $20 \%$. The calculated $\mathrm{OH}^{*} / \mathrm{CH}(\mathrm{A})^{*}$ chemiluminescent intensity ratios varied with ER non-monotonically in the methane-propane blended fuel flames, see Figure. 11. The numerical results also shown that the addition of propane caused a reduction of the $\mathrm{OH}^{*} / \mathrm{CH}(\mathrm{A})^{*}$ chemiluminescent intensity ratio. Only $5 \%$ of $\mathrm{C}_{3} \mathrm{H}_{8}$ blended into methane reduced the peak of the $\mathrm{OH}^{*} / \mathrm{CH}(\mathrm{A})^{*}$ chemiluminescent intensity ratio from 16 to 7 and further reduced to 3.5 for the blends with $20 \%$ of $\mathrm{C}_{3} \mathrm{H}_{8}$. Moreover, it was observed that the equivalence ratio of the peak $\mathrm{OH}^{*} / \mathrm{CH}_{(\mathrm{A})}{ }^{*}$ chemiluminescent intensity ratio shifted from 0.7 in methane flames to stoichiometry for the $5 \% \mathrm{C}_{3} \mathrm{H}_{8}$ blends 
and further shifted to rich with the increase of $\mathrm{C}_{3} \mathrm{H}_{8}$ mole fraction in the blends, shown in Figure. 10 and Figure. 11. In summary, the calculation indicated that small changes of fuel composition can affect the $\mathrm{OH}^{*} / \mathrm{CH}(\mathrm{A})^{*}$ chemiluminescent intensity ratio behaviour dramatically, benefiting from the shift of the peak $\mathrm{OH}^{*} / \mathrm{CH}(\mathrm{A})^{*}$ chemiluminescent intensity ratio equivalence ratio, the $\mathrm{OH}^{*} / \mathrm{CH}(\mathrm{A})^{*}$ chemiluminescent intensity ratio can be used to monitor the ER in lean flames.

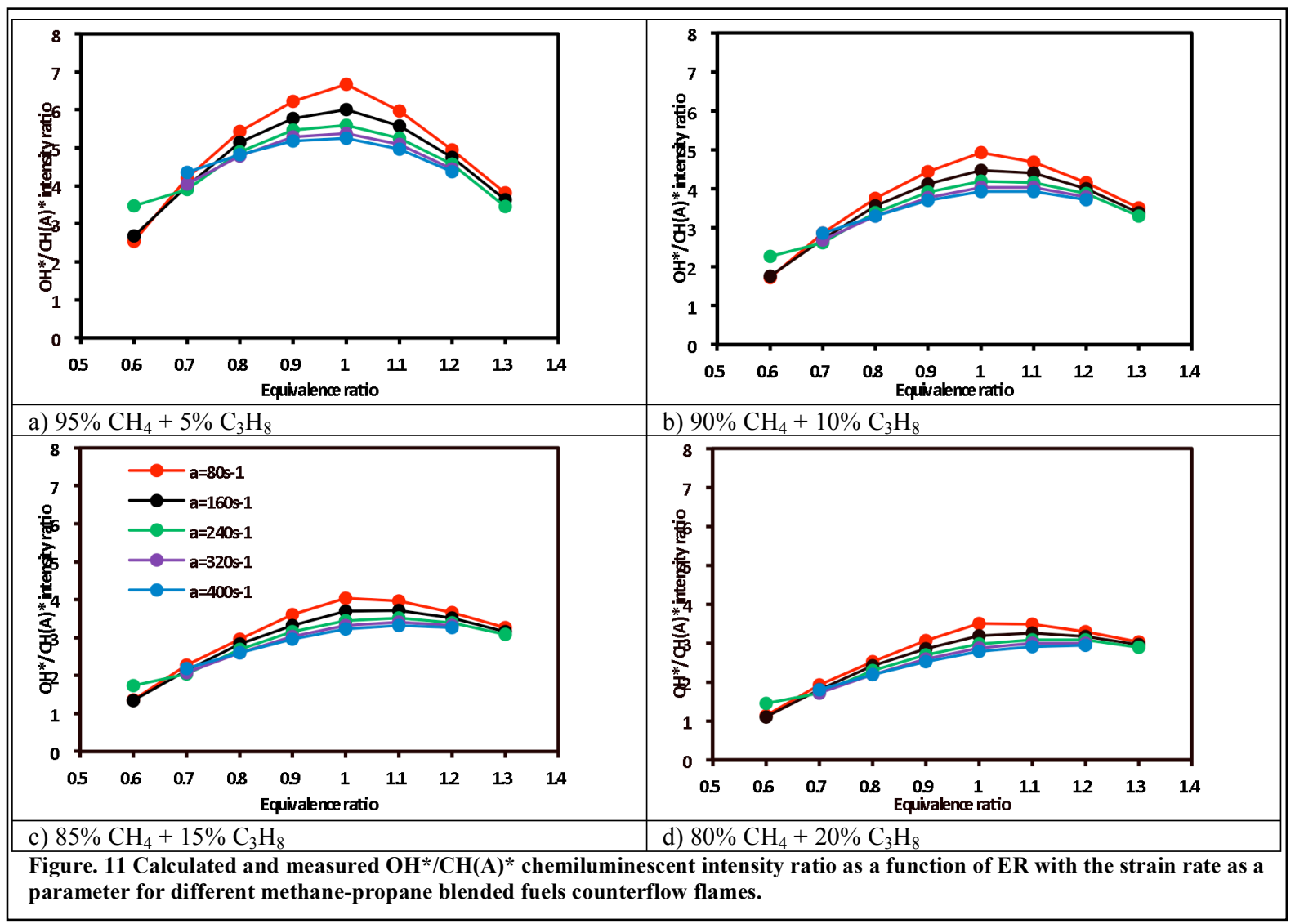

\section{Summary}

The main findings of the current study are summarised as follows.

- Both the experimental and numerical results demonstrate the ability of $\mathrm{OH}^{*}, \mathrm{CH}^{*}$ and $\mathrm{CO}_{2}{ }^{*}$ chemiluminescent intensities to mark HRR location in methane/air counterflow flames.

- Overall, the equivalence ratio has a more prominent effect on the chemiluminescent intensity as compared to the effect of the strain rate.

- The experimental results showed that the $\mathrm{OH}^{*} / \mathrm{CH}(\mathrm{A})^{*}$ chemiluminescent intensity ratio is highly dependent on the equivalence ratio and there is nearly no effect of strain rate. Thus, it can be used to monitor the equivalence ratio.

- The considered chemiluminescence detailed chemistry sub-model in this study is able to predict the intensity of $\mathrm{OH}^{*}$ and $\mathrm{CH}(\mathrm{A})^{*}$ very well, but only a fair agreement is achieved between calculated and measured chemiluminescent intensity ratio of $\mathrm{OH}^{*} / \mathrm{CH}(\mathrm{A})^{*}$. It is noted that the addition of Hydrogen related reactions to the $\mathrm{OH}^{*}$ chemiluminescence detailed chemistry leads to improved comparison with the experimental results, in particular for low values of equivalence ratio.

- The effect of the contribution of background emissions due to $\mathrm{CO} 2 *$ chemiluminescence on the $\mathrm{OH}^{*} / \mathrm{CH}(\mathrm{A})^{*}$ chemiluminescent intensity ratio and its dependence on equivalence ratio and flow strain rate was evaluated.

- The $\mathrm{OH}^{*} / \mathrm{CH}(\mathrm{A})^{*}$ chemiluminescent intensity ratio was calculated for the first time in methane-propane blended fuel counterflow flames and showed that the addition of propane changes significantly the behaviour observed in purely methane flames. The results demonstrate that the $\mathrm{OH}^{*} / \mathrm{CH}(\mathrm{A})^{*}$ chemiluminescent intensity ratio can be used to monitor the ER in the lean methane-propane blended fuel flames. 
- The experimental and numerical methods can provide information about the local and global chemiluminescent emission in methane and methane-based blends counterflow flames. Therefore, a chemiluminescence sensor can be developed for monitoring HRR location and equivalence ratio and can potentially be used for control of gas turbine combustors.

\section{Acknowledgments}

The authors would like to acknowledge the support of Engineering and Physical Sciences Research Council (EPSRC) through grant EP/K021095/1 and the financial support of the China Scholarship Council (CSC).

\section{References}

${ }^{1}$ Kathrotia, T., Riedel, U., Seipel, A., Moshammer, K., and Brockhinke, A. "Experimental and numerical study of chemiluminescent species in low-pressure flames," Applied Physics B Vol. 107, No. 3, 2012, pp. 571584.

${ }^{2}$ Gaydon, A. G. The spectroscopy of flames, 1957.

${ }^{3}$ Slack, M., and Grillo, A. "High temperature rate coefficient measurements of $\mathrm{CO}+\mathrm{O}$ chemiluminescence," Combustion and Flame Vol. 59, No. 2, 1985, pp. 189-196.

${ }^{4}$ Kopp, M., Brower, M., Mathieu, O., Petersen, E., and Güthe, F. " $\mathrm{CO}_{2}{ }^{*}$ chemiluminescence study at low and elevated pressures," Applied Physics B Vol. 107, No. 3, 2012, pp. 529-538.

${ }^{5}$ Hardalupas, Y., and Orain, M. "Local measurements of the time-dependent heat release rate and equivalence ratio using chemiluminescent emission from a flame," Combustion and Flame Vol. 139, No. 3, 2004, pp. 188-207.

${ }^{6}$ Hardalupas, Y., Panoutsos, C., and Taylor, A. "Spatial resolution of a chemiluminescence sensor for local heat-release rate and equivalence ratio measurements in a model gas turbine combustor," Experiments in fluids Vol. 49, No. 4, 2010, pp. 883-909.

${ }^{7}$ Ikeda, Y., Kojima, J., and Hashimoto, H. "Local chemiluminescence spectra measurements in a highpressure laminar methane/air premixed flame," Proceedings of the Combustion Institute Vol. 29, No. 2, 2002, pp. $1495-1501$.

${ }^{8}$ Higgins, B., McQuay, M., Lacas, F., Rolon, J.-C., Darabiha, N., and Candel, S. "Systematic measurements of $\mathrm{OH}$ chemiluminescence for fuel-lean, high-pressure, premixed, laminar flames," Fuel Vol. 80, No. 1, 2001, pp. 67-74.

${ }^{9}$ Muruganandam, T., Kim, B.-H., Morrell, M., Nori, V., Patel, M., Romig, B., and Seitzman, J. "Optical equivalence ratio sensors for gas turbine combustors," Proceedings of the Combustion Institute Vol. 30, No. 1, 2005, pp. 1601-1609.

${ }^{10}$ Guethe, F., Guyot, D., Singla, G., Noiray, N., and Schuermans, B. "Chemiluminescence as diagnostic tool in the development of gas turbines," Applied Physics B Vol. 107, No. 3, 2012, pp. 619-636.

${ }^{11}$ Muruganandam, T., Kim, B., Olsen, R., Patel, M., Romig, B., and Seitzman, J. "Chemiluminescence based sensors for turbine engines," AIAA paper Vol. 4490, 2003.

${ }^{12}$ Nori, V., and Seitzman, J. "Chemiluminescence measurements and modeling in syngas, methane and jet-A fueled combustors," 45th AIAA Aerospace Sciences Meeting and Exhibit, Reno, NV, January. 2007, pp. 811 .

${ }^{13}$ Samaniego, J.-M., Egolfopoulos, F., and Bowman, C. "CO2* chemiluminescence in premixed flames," Combustion Science and Technology Vol. 109, No. 1-6, 1995, pp. 183-203.

${ }^{14}$ Ballester, J., Hernández, R., Sanz, A., Smolarz, A., Barroso, J., and Pina, A. "Chemiluminescence monitoring in premixed flames of natural gas and its blends with hydrogen," Proceedings of the Combustion Institute Vol. 32, No. 2, 2009, pp. 2983-2991.

${ }^{15}$ Cipriano, A., Gasperetti, S., Mariotti, G., and Paganini, E. "Analysis of the Spectral Properties of Premixed, Diffusion, and Hybrid Natural Gas Flames," ASME Turbo Expo 2004: Power for Land, Sea, and Air. American Society of Mechanical Engineers, 2004, pp. 313-320.

${ }^{16}$ Jeong, Y. K., Jeon, C. H., and Chang, Y. J. "Evaluation of the equivalence ratio of the reacting mixture using intensity ratio of chemiluminescence in laminar partially premixed $\mathrm{CH}$ 4-air flames," Experimental thermal and fluid science Vol. 30, No. 7, 2006, pp. 663-673.

${ }^{17}$ Kojima, J., Ikeda, Y., and Nakajima, T. "Basic aspects of OH (A), CH (A), and C 2 (d) chemiluminescence in the reaction zone of laminar methane-air premixed flames," Combustion and Flame Vol. 140, No. 1, 2005, pp. 34-45.

${ }^{18}$ Kojima, J., Ikeda, Y., and Nakajima, T. "Multi-point time-series observation of optical emissions for flame-front motion analysis," Measurement Science and Technology Vol. 14, No. 9, 2003, p. 1714.

${ }^{19}$ Orain, M., and Hardalupas, Y. "Effect of fuel type on equivalence ratio measurements using chemiluminescence in premixed flames," Comptes Rendus Mecanique Vol. 338, No. 5, 2010, pp. 241-254. 
${ }^{20}$ Panoutsos, C. S., Hardalupas, Y., and Taylor, A. M. K. P. "Numerical evaluation of equivalence ratio measurement using $\mathrm{OH} *$ and $\mathrm{CH} *$ chemiluminescence in premixed and non-premixed methane-air flames," Combustion and Flame Vol. 156, No. 2, 2009, pp. 273-291.

${ }^{21}$ García-Armingol, T., and Ballester, J. "Influence of fuel composition on chemiluminescence emission in premixed flames of $\mathrm{CH} 4 / \mathrm{CO} 2 / \mathrm{H} 2 / \mathrm{CO}$ blends," International Journal of Hydrogen Energy Vol. 39, No. 35, 2014, pp. 20255-20265.

${ }^{22}$ García-Armingol, T., and Ballester, J. "Flame chemiluminescence in premixed combustion of hydrogen-enriched fuels," International Journal of Hydrogen Energy Vol. 39, No. 21, 2014, pp. 11299-11307.

${ }^{23}$ Docquier, N., Lacas, F., and Candel, S. "Closed-loop equivalence ratio control of premixed combustors using spectrally resolved chemiluminescence measurements," Proceedings of the Combustion Institute Vol. 29, No. 1, 2002, pp. 139-145.

${ }^{24}$ García-Armingol, T., Ballester, J., and Smolarz, A. "Chemiluminescence-based sensing of flame stoichiometry: influence of the measurement method," Measurement Vol. 46, No. 9, 2013, pp. 3084-3097.

${ }^{25}$ Zimmer, L., Tachibana, S., Yamamoto, T., Kurosawa, Y., and Suzuki, K. "Evaluation of chemiluminescence as sensor for lean premixed combustion," Continuum Vol. 387, 2003, p. 431.4.

${ }^{26}$ Lauer, M., and Sattelmayer, T. "On the adequacy of chemiluminescence as a measure for heat release in turbulent flames with mixture gradients," Journal of Engineering for Gas Turbines and Power Vol. 132, No. 6, 2010, p. 061502.

${ }^{27}$ Kathrotia, T., Riedel, U., and Warnatz, J. "A numerical study on the relation of $\mathrm{OH}^{*}, \mathrm{CH}^{*}$, and $\mathrm{C} 2 *$ chemiluminescence and heat release in premixed methane flames," Proceedings of the European combustion Meeting. 2009, pp. 1-5.

${ }^{28}$ Kopp, M. M., Mathieu, O., and Petersen, E. L. "Rate Determination of the CO2* Chemiluminescence Reaction $\mathrm{CO}+\mathrm{O}+\mathrm{M} \rightleftarrows \mathrm{CO} 2 *+\mathrm{M}$," International Journal of Chemical Kinetics Vol. 47, No. 1, 2015, pp. 50-72.

${ }^{29}$ Smith, G. P., Park, C., Schneiderman, J., and Luque, J. "C 2 Swan band laser-induced fluorescence and chemiluminescence in low-pressure hydrocarbon flames," Combustion and Flame Vol. 141, No. 1, 2005, pp. 66-77.

${ }^{30}$ Hall, J. M., and Petersen, E. L. "An optimized kinetics model for $\mathrm{OH}$ chemiluminescence at high temperatures and atmospheric pressures," International journal of chemical kinetics Vol. 38, No. 12, 2006, pp. 714-724.

${ }^{31}$ Bozkurt, M. "Shock-tube investigation of key reactions for chemiluminescence in various combustion systems," 2013.

${ }^{32}$ Katsikadakos, D. "Theoretical and experimental investigation of n-butanol combustion," Ph.D. Dissertation, Imperial College London, Mehcnaical Engineering Dept., London, 2013.

${ }^{33}$ Akamatsu, F., Wakabayashi, T., Tsushima, S., Katsuki, M., Mizutani, Y., Ikeda, Y., Kawahara, N., and Nakajima, T. "The development of a light-collecting probe with high spatial resolution applicable to randomly fluctuating combustion fields," Measurement Science and Technology Vol. 10, No. 12, 1999, p. 1240.

${ }^{34}$ Kojima, J., Ikeda, Y., and Nakajima, T. "Spatially resolved measurement of $\mathrm{OH}^{*}, \mathrm{CH}^{*}$, and $\mathrm{C}^{*}$ chemiluminescence in the reaction zone of laminar methane/air premixed flames," Proceedings of the Combustion Institute Vol. 28, No. 2, 2000, pp. 1757-1764.

${ }^{35}$ Smith, G. P., Golden, D. M., Frenklach, M., Moriarty, N. W., Eiteneer, B., Goldenberg, M., Bowman, C. T., Hanson, R. K., Song, S., and Gardiner Jr, W. C. "GRI-Mech 3.0," URL: http://www. me. berkeley. edu/gri mech Vol. 51, 1999, p. 55.

${ }^{\overline{36}}$ Burcat, A., and Ruscic, B. "Ideal gas thermodynamic data in polynomial form for combustion and air pollution use," Available from: The latest version of this database is available by anonymous FTP from ftp://ftp. technion. ac. il/pub/supported/aetdd/thermodynamics. There is a web-based mirror, http://gar; eld. chem. elte. hu/Burcat/burcat. html, in Europe.(2004-1997)(cited 20 December 2008), 2007.

${ }^{37}$ Lutz, A. E., Kee, R. J., Grcar, J. F., and Rupley, F. M. "OPPDIF: A Fortran program for computing opposed-flow diffusion flames." Sandia National Labs., Livermore, CA (United States), 1997.

${ }^{38}$ Nori, V. N., and Seitzman, J. M. "CH* chemiluminescence modeling for combustion diagnostics," Proceedings of the Combustion Institute Vol. 32, No. 1, 2009, pp. 895-903. 